\title{
ELIZABETHAN MUSIC AND MUSICAL CRITICISM
}




\section{PARTHENIA IN-VIOLATA. \\ OR}

Mayden-Musicke for the Virginalls and? Bass-U iol

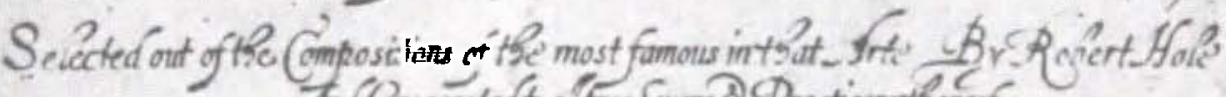

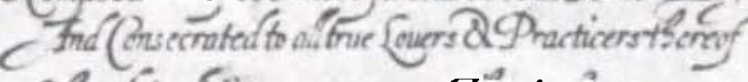

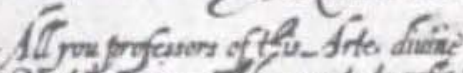

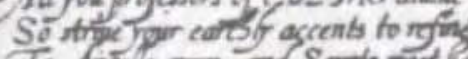

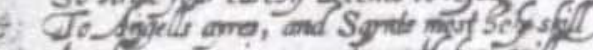

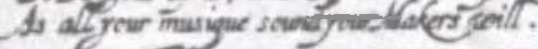

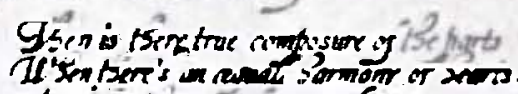

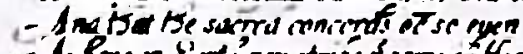

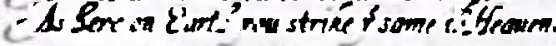

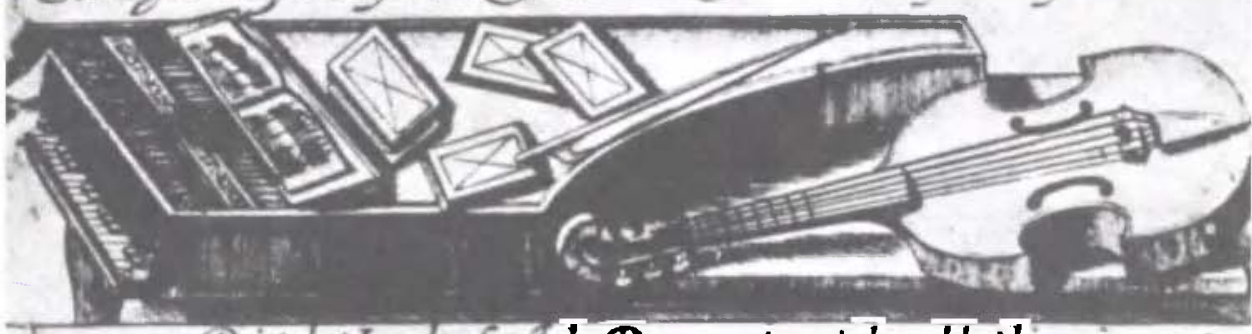

Printed at London for Jo Prper, and an to be sold at bs

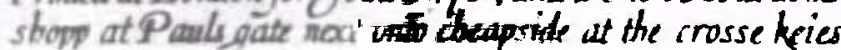




\section{ELIZABETHAN MUSIC}

\section{and}

\section{Musical Criticism}

By

MORRISON COMEGYS BOYD

SECOND EDITION

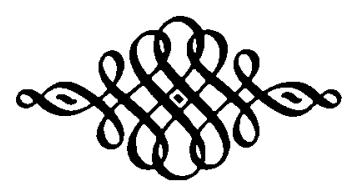

p

Philadelphia

University of Pennsylvania Press 
(C) 1940,1962 , by The Trustees of the University of Pennsylvania Library of Congress Catalog Card Number: 62-10744

Second Edition, Revised, 1962

Second Printing, with corrections, 1967

First Pennsyltania Paperback edition 1974

ISBN: $0 \cdot 8122 \cdot 1071-9$

Printed in the United States of America 
To

Miss Amy Comegys 
